\title{
Effects of Bearing Type on Seismic Response of Small Base Isolation System Using Friction Bearings
}

\author{
Katsumi Kurita ${ }^{1}$, Mikito Kezuka ${ }^{1}$, Shigeru Aoki ${ }^{1}$, Yuuji Nakanishi ${ }^{2}$, Kazutoshi Tominaga ${ }^{2}$ and Mitsuo Kanazawa ${ }^{3}$ \\ 1. Department of Mechanical Engineering, Tokyo Metropolitan College of Industrial Technology, Tokyo 140-0011, Japan \\ 2. Department of Production Systems Engineering, Tokyo Metropolitan College of Industrial Technology, Tokyo 140-0011, Japan \\ 3. Kanazawa Seisakusyo Co., Ltd., Tokyo 141-0031, Japan
}

\begin{abstract}
In this study, dynamic characteristics of the small base isolation system using new friction bearings are investigated by excitation experiment, and compared to other one using previous bearings. Peak amplitude of the acceleration response waves on the small base isolation system is decreased to about $10 \%-25 \%$ compared to the input waves. Also root mean square amplitude is decreased to about $10 \%-40 \%$. In case of the ball embedded a cylindrical sponge, the new bearing, the damping ratio increases with increasing width of the cylindrical sponge. The natural frequency does not change. On the other hand, in case of the marble plate that is previous bearing, the damping ratio increases with increasing curvature radius of the marble plate, the natural frequency also increases. Therefore, the small base isolation system using new friction bearing provides better performance. The responses of the base isolation system indicate nonlinier effects by friction force.
\end{abstract}

Key words: Small base isolation system, friction bearing, peak amplitude, natural frequency, damping ratio.

\section{Introduction}

In order to prevent serious damage of building structures by seismic ground motion, it is important to reinforce structures. So, existing buildings that do not meet earthquake resistance standards are being retrofitted in conformity with the modern seismic codes. Generally, seismic retrofitting uses a technique of reinforcing by shear trusses etc. [1]. However, it just only withstands vibration by seismic ground motion, cannot decrease vibration inside buildings. Therefore, instability equipment such as computer severs and works of art installed inside buildings will turn over during a big earthquake. So some small base isolation systems that can easily be installed inside buildings are developed for them [2]. For example, roller type using liner rail isolation device [3] and friction pendulum isolation device with poly-curvature rail [4, 5] are used. However,

Corresponding author: Katsumi Kurita, Ph.D., associate professor, research fields: earthquake engineering and seismology. E-mail: katsumi@s.metro-cit.ac.jp. mechanisms of them are complicated, it is not easy to install.

We have developed a simple device using friction force to reduce seismic response [6]. And dynamic characteristics of this system were investigated by excitation experiment using artificial seismic waves [7]. In case of the small base isolation system using steel ball type friction bearings, the reduction of seismic response is expected when the input wave does not include the component of natural frequency of on this system. Otherwise, a big amplification by resonance occurs. To prevent amplification, a combination of the ball type friction bearings and the marble plate type friction bearings that generates high damping, was used on this system. However, the upper plate on this system indicates unstable motion because of friction force with eccentricity. Therefore, it needs to use same type friction bearing on this system. So we propose a new friction bearing that consists of a ball embedded a cylindrical sponge.

In this study, dynamic characteristics of the small 
base isolation system using new friction bearings are investigated by excitation experiment, and are compared with the small base isolation system using previous bearings.

\section{Friction Bearings}

A friction bearing is shown in Fig. 1. It consists of two plates having a ball or/and a marble plate. The spherical concaves plate, the ball and the marble plate are made of acryl. Size of the plate is $200 \mathrm{~mm} \times 200$ $\mathrm{mm}$. Also, radius of concave is $450 \mathrm{~mm}$. The ball or the marble plate slides between two plates, and vibration of the shaking table is transmitted to the upper plate via them. Since restoring force is generated when the ball or the marble plate bearing uplifts, two plates return to original position.

In this study, a new friction bearing that consists of a ball embedded a cylindrical sponge is prepared (Fig. 2). The cylindrical sponge is made of poly chloroprene.

The small base isolation system composed of friction bearings is shown in Fig. 3. This device is placed at each corner. Combination of friction bearings on this experiment is shown in Table 1.

\section{Restoring Force Characteristics and Friction Coefficients}

To understand restring force characteristics of this system, static load test is done. Examples of restring force characteristics are shown in Fig. 4. And static

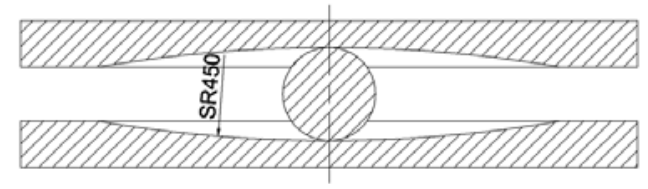

(a)

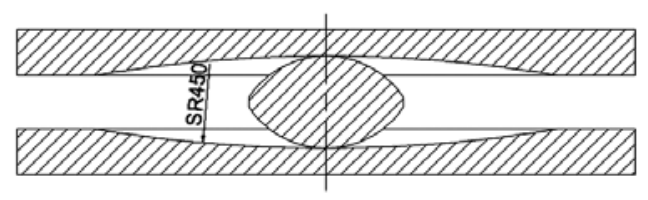

(b)

Fig. 1 Friction bearings: (a) ball type; (b) marble plate type.
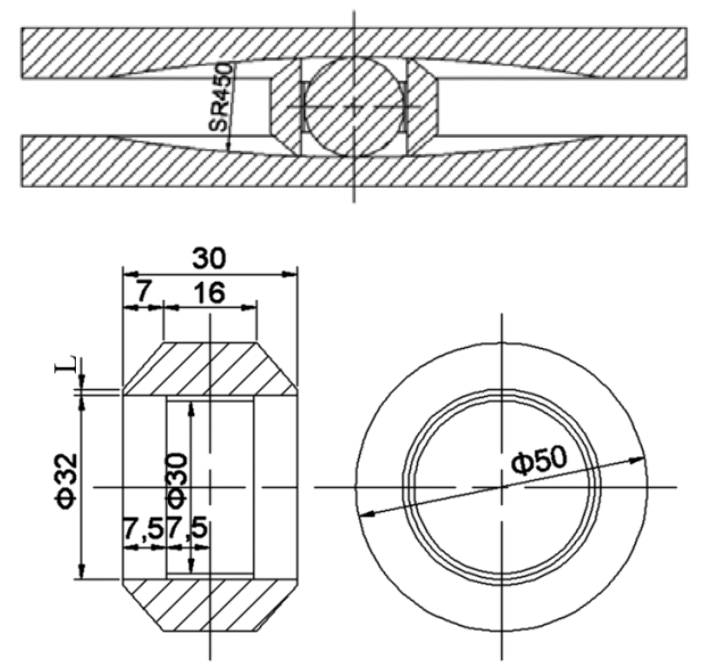

Fig. 2 New friction bearing with a ball embedded a cylindrical sponge.

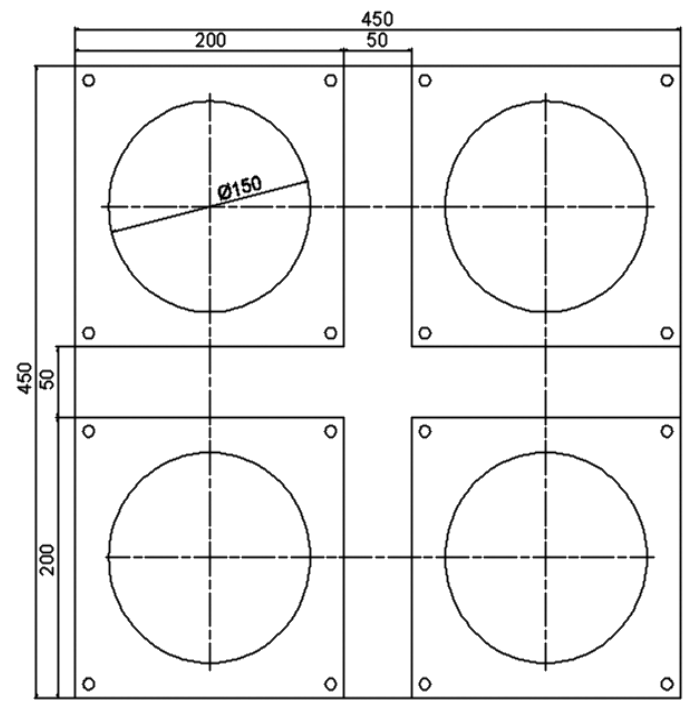

Fig. 3 Small base isolation system composed of friction bearings (mm).

Table 1 Experimental conditions.

\begin{tabular}{ll}
\hline Case & Experimental condition \\
\hline Case 1 & 4 Balls \\
Case 2 & 4 Marble plates (SR30) \\
Case 3 & 4 Marble plates (SR80) \\
Case 4 & 4 Ball + rubber ring L $=1 \mathrm{~mm}$ \\
Case 5 & 4 Ball + rubber ring L $=3 \mathrm{~mm}$ \\
\hline
\end{tabular}

friction coefficients calculated from restring force characteristics are shown in Table 2.

Since the tumbling motion acts in a dominant fashion in Case 1, the static friction coefficient could not measured. The increasing rate of the restoring 

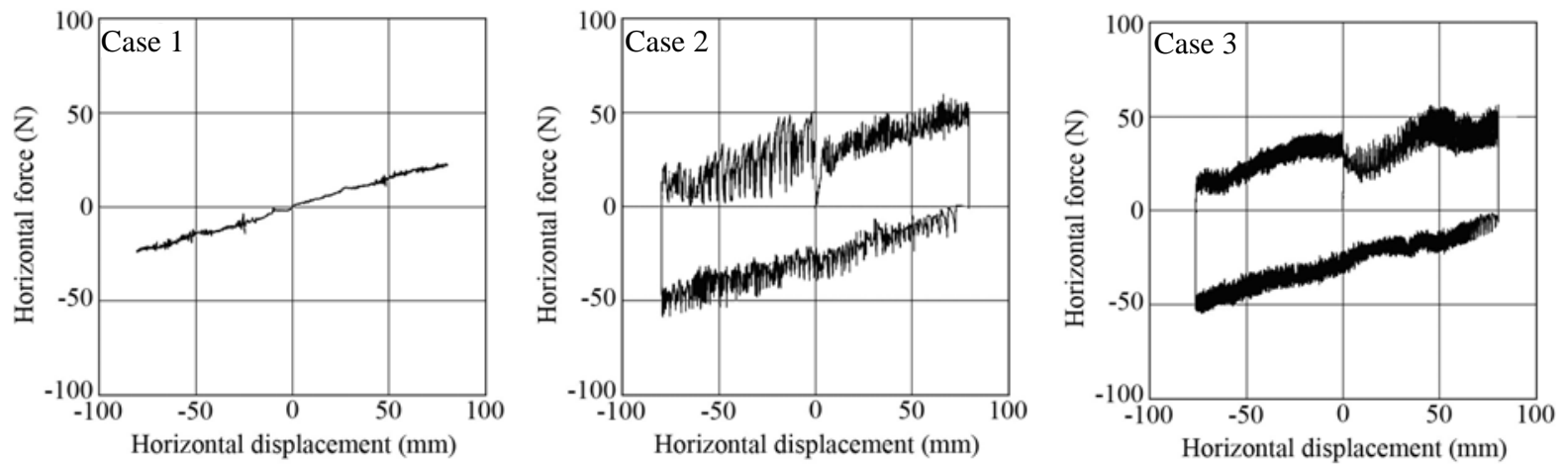

Fig. 4 Examples of restoring force characteristics on this system.

Table 2 Coefficients of static friction.

\begin{tabular}{ll}
\hline Case & Coefficient of static friction \\
\hline Case 2 & 0.106 \\
Case 3 & 0.152 \\
Case 4 & 0.087 \\
Case 5 & 0.202 \\
\hline
\end{tabular}

force is constant. On the other hand, the restring force characteristics in Case 2-Case 5 show the type of a motion with friction force. The restoring force of them indicates repeatedly increasing and decreasing. It means that the motion of the marble plate acts rolling and sliding motion repeatedly.

\section{Excitation Experiments}

To understand dynamic characteristics of the small base isolation system, excitation experiments of this system are done using artificial seismic waves. This system that installed a weight with $9 \mathrm{~kg}$ is put on the shaking table. Acceleration sensors (Kyowa AS-2GA) are installed on the shaking table and on this system. Signal from acceleration sensors is recorded to a PC through an interface (Kyowa PCD-300A). Sampling rate is $0.01 \mathrm{~s} /$ points.

\subsection{Acceleration Response Waveforms}

Acceleration response waveforms recorded on the upper plate of the small base isolation system are shown in Fig. 5. Although reduction behaviors are different between other cases except Case 1, the amplitude of acceleration response waveforms are decreased, compared with the input waveforms.
Peak amplitude and RMS (root mean square) amplitude of the acceleration response waveforms are shown in Table 3. Peak amplitudes of the acceleration response waveforms on the small base isolation system, except in Case 1, are decreased to about $10 \%-25 \%$ compared to the input waves. Also RMS are decreased to about $10 \%-40 \%$. The best case estimated from results of peak amplitude and RMS is Case 4. In Case 1, amplitude of the acceleration response waveform until $20 \mathrm{~s}$ are smaller compared to the input wave. The wave with a period of $2 \mathrm{~s}$ is identified at $15 \mathrm{~s}$, and amplification by resonance is generated.

\subsection{Fourier Spectra}

Fourier spectra of acceleration response waves recorded on the small base isolation system are shown in Fig. 6. Comparing the Fourier spectrum of the input wave, the Fourier spectrum in Case 4 is clearly reduced over $1 \mathrm{~Hz}$, while it starts to reduce from 2-3 $\mathrm{Hz}$ in other cases.

\subsection{Natural Period and Damping Ratio}

Fitting a theoretical transfer function for the spectral ratio that divided the Fourier spectrum of the input wave into the Fourier spectrum of response on this system by a forwarding model, then the natural period and the damping ratio that are very important factors to control this system are evaluated. In this case, a model of single degree of freedom system with spring and damper is used. And the damping ratio in 

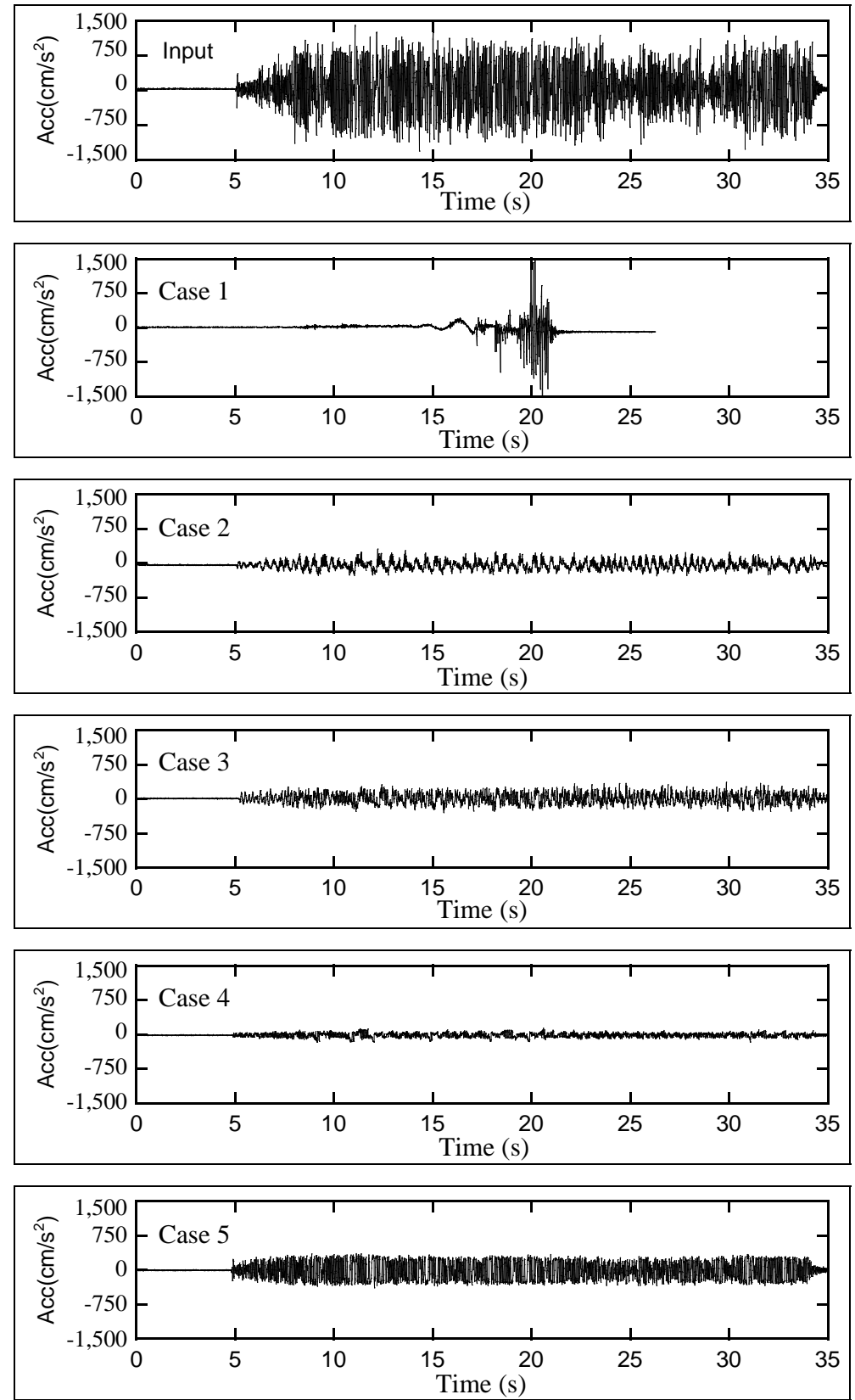

Fig. 5 Input and acceleration response waveforms.

Table 3 Results of excitation experiment.

\begin{tabular}{clllll}
\hline \multirow{2}{*}{ Case } & \multicolumn{2}{c}{$\begin{array}{c}\text { Peak acceleration } \\
\text { amplitude (gal) }\end{array}$} & & \multicolumn{2}{c}{ RMS (gal) } \\
\cline { 2 - 3 } \cline { 5 - 6 } \cline { 5 - 5 } & Input & Response & & Input & Response \\
\hline Case 1 & $1,230.5$ & $1,649.0$ & & 374.1 & 139.1 \\
Case 2 & $1,367.3$ & 346.0 & & 421.0 & 87.0 \\
Case 3 & $1,351.3$ & 352.2 & & 421.2 & 95.6 \\
Case 4 & $1,344.9$ & 151.4 & & 433.5 & 41.5 \\
Case 5 & $1,436.3$ & 382.7 & & 443.7 & 95.6 \\
\hline
\end{tabular}

Case 1 that the friction coefficient is smallest in this experiment is calculated by logarithmic decrement.

An example of fitting the theoretical transfer function to the spectral ratio is shown in Fig. 7, and estimated natural frequency and damping ratio are shown in Table 4. In case of the marble plate, although the damping ratio increases with increasing curvature radius of the marble plate, also the natural 

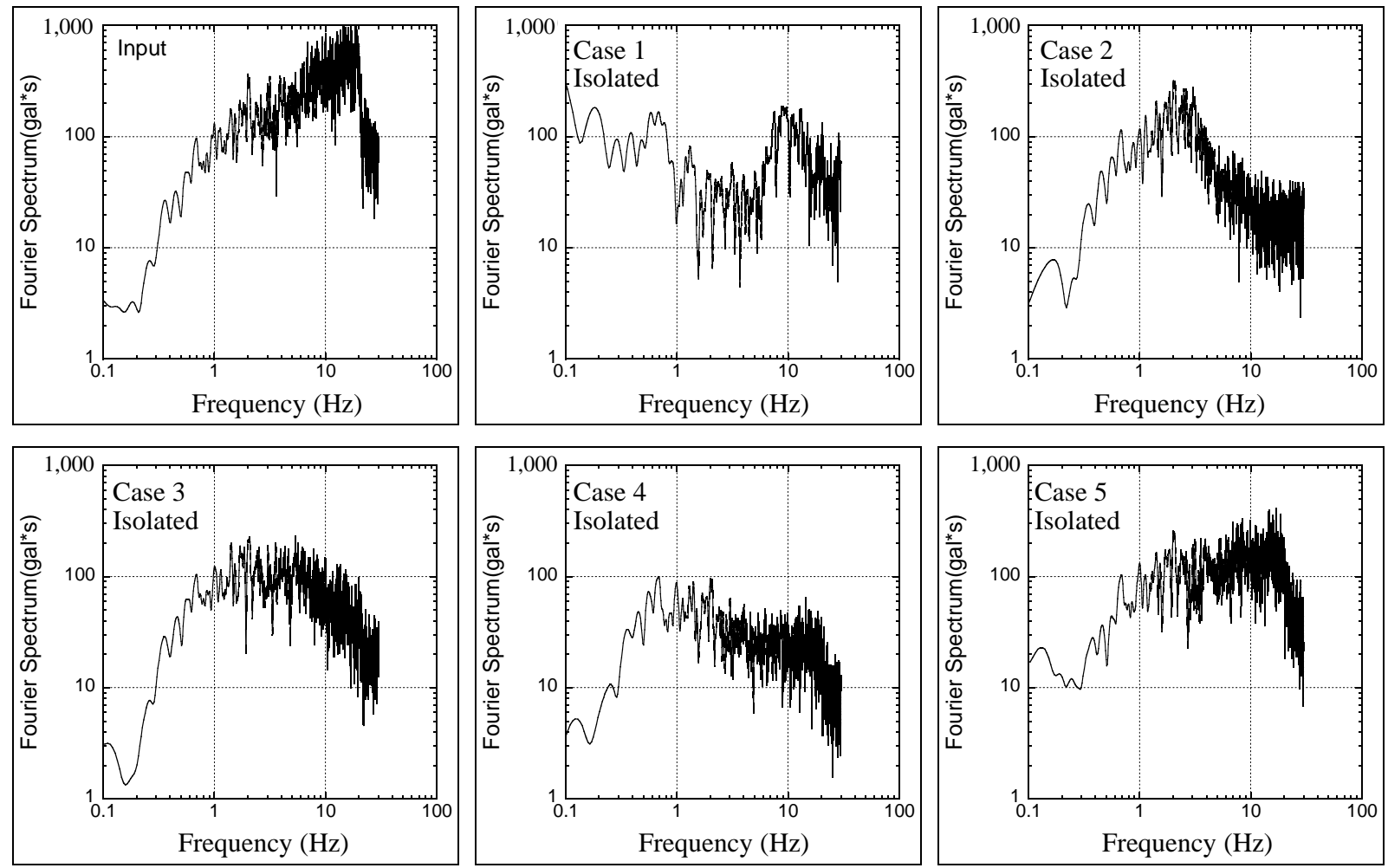

Fig. 6 Fourier spectra of input and response waveforms.

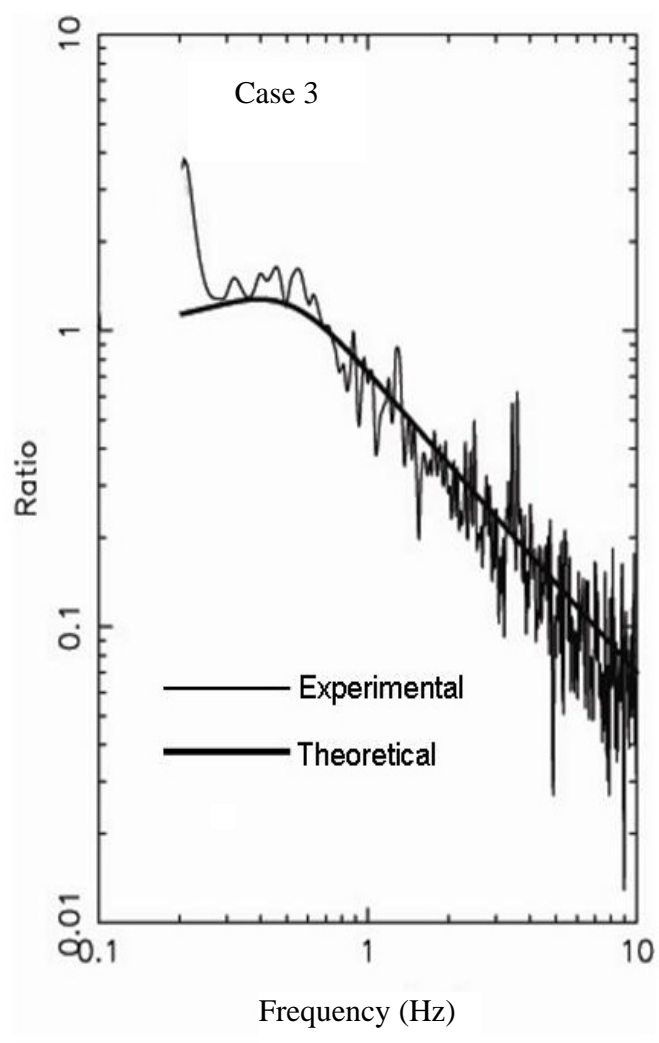

Fig. 7 An example of fitting a theoretical transfer function to the spectral ratio (Response/Input).
Table 4 Natural frequency and damping ratio.

\begin{tabular}{lll}
\hline Case & Natural frequency $(\mathrm{Hz})$ & Damping ratio \\
\hline Case 1 & 0.54 & 0.02 \\
Case 2 & 2.00 & 0.40 \\
Case 3 & 0.70 & 2.00 \\
Case 4 & 0.50 & 0.60 \\
Case 5 & 0.50 & 3.00 \\
\hline
\end{tabular}

frequency increases. So it is impossible to reduce the seismic response at the low band frequency. Increasing contact area between the marble plate and the spherical concaves plate, the stiffness between them increases. Therefore, the natural frequency also increases from a spring-mass system point of view. On the other hand, the damping ratio increases with increasing in width of the cylindrical sponge. However, the natural frequency does not change unlike a case of the marble plate. The stiffness of cylindrical sponge is smaller comparing materials between a cylindrical sponge and an acrylic. Therefore a stiffness variation of cylindrical sponge is very small with increasing width of the cylindrical sponge. 


\section{Numerical Analysis}

\subsection{Analysis Model of the Base Isolation System}

For evaluation, the base isolation system is approximately modeled by linier single degree of freedom system with a spring and a damper (Fig. 8).

The equation of motion is as followings:

$$
\ddot{x}+2 \zeta \omega_{n}(\dot{x}-\dot{y})+\omega_{n}(x-y)=0
$$

where, $\zeta$ is damping ratio, $\omega_{n}$ is natural angular frequency, $x, \dot{x}, \ddot{x}$ are displacement, velocity and acceleration of the base isolation system, and $y, \dot{y}$ are displacement and velocity of an input motion. And natural frequency and damping ratio for this analysis are used the values shown in Table 4 evaluated in the Section 4.3. The calculation is done in frequency domain.

\subsection{Comparison the Waveforms between Excitation} Experiment and Numerical Analysis

An example of comparison between them is shown in Fig. 9, and peak acceleration amplitude and RMS are shown in Tables 5 and 6. Peak acceleration amplitude on numerical analysis is bigger than that on excitation experiment, and the difference between them is up to $30 \%$. The waveform on numerical analysis indicates some big spikes consisting of long period. On the other hand, the waveform on excitation experiment does not show some spikes but rectangular wave. Velocity at peak amplitude in acceleration is equal to zero. Since the friction force that is generated between the spherical concaves plate and the marble plate or the sponge changes from kinetic friction force to static friction force, the sliding between them stops while the force generated by vibration is under the maximum static friction force. So the waveform on excitation experiment shows rectangular wave, and peak amplitude on excitation experiment is lower than

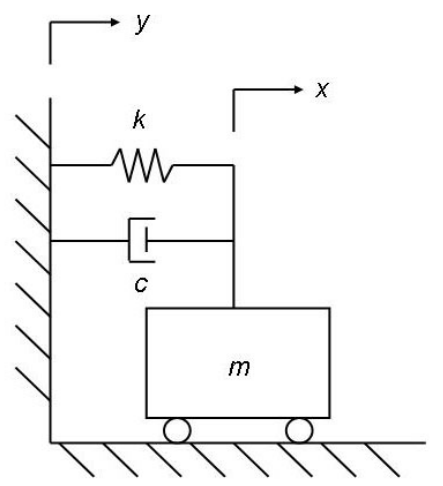

Fig. 8 Analytical model for acceleration response waveforms.

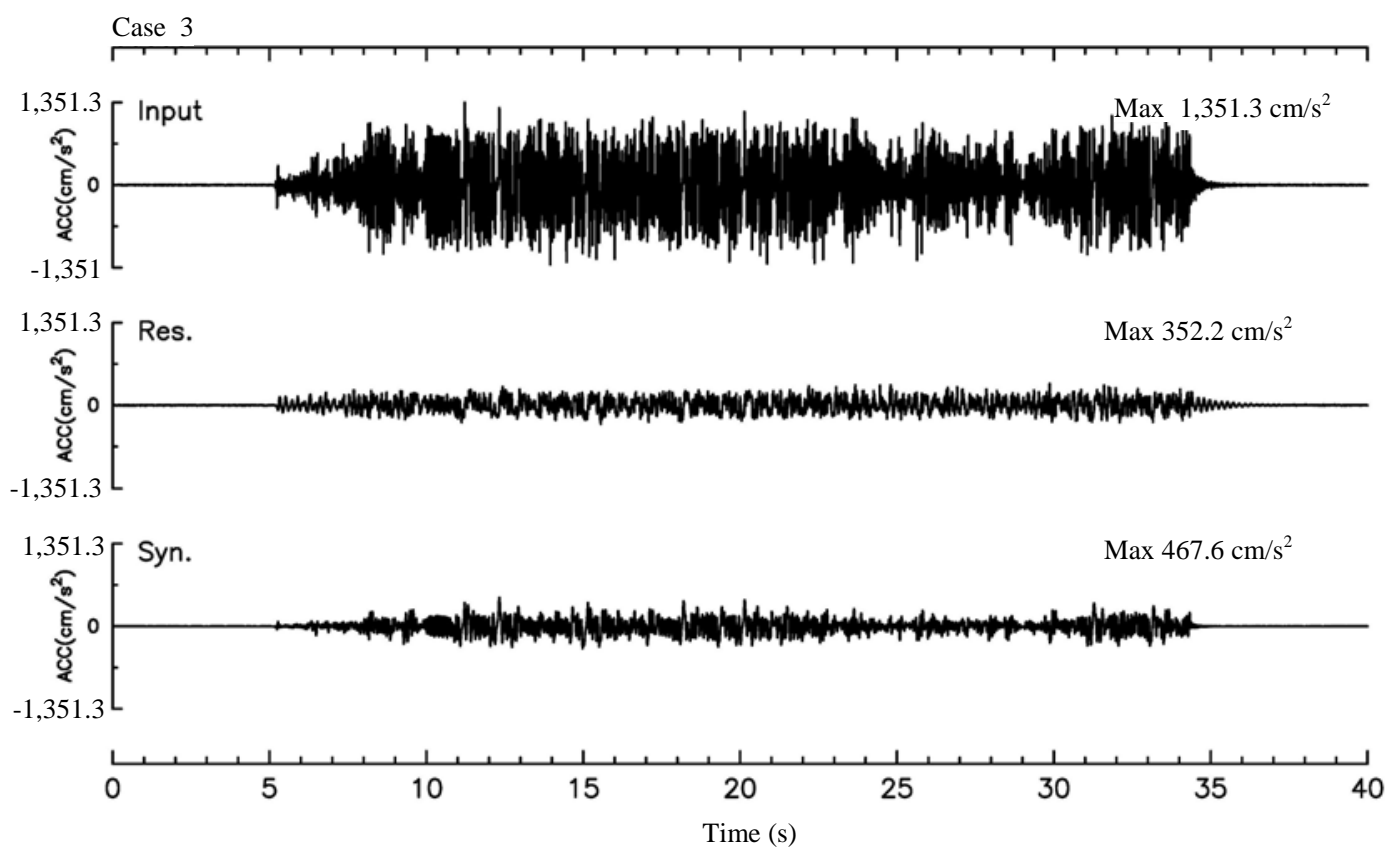

Fig. 9 An example of comparison between experimental and numerical waveform. 
Table 5 Comparison of peak acceleration amplitude between experiment and numerical analysis.

\begin{tabular}{lll}
\hline \multirow{2}{*}{ Case } & \multicolumn{2}{c}{ Peak acceleration amplitude (gal) } \\
\cline { 2 - 3 } & Experimental & Numerical \\
\hline Case 2 & 346.0 & 504.3 \\
Case 3 & 352.2 & 467.6 \\
Case 4 & 151.4 & 161.6 \\
Case 5 & 382.7 & 519.9 \\
\hline
\end{tabular}

Table 6 Comparison of RMS between experiment and numerical analysis.

\begin{tabular}{llc}
\hline \multirow{2}{*}{ Case } & \multicolumn{2}{c}{ RMS (gal) } \\
\cline { 2 - 3 } & Experimental & Numerical \\
\hline Case 2 & 87.0 & 95.9 \\
Case 3 & 95.6 & 104.4 \\
Case 4 & 41.5 & 33.1 \\
Case 5 & 95.6 & 115.0 \\
\hline
\end{tabular}

that on numerical analysis. This is a nonlinier phenomenon of friction force. Except for the spike parts on numerical analysis, the shape of waveform is exactly similar to that on excitation experiment.

\section{Conclusions}

To investigate dynamic characteristics of the small base isolation system using new friction bearings, excitation experiments were done, and dynamic characteristics between the new friction bearings and the previous bearings are compared. As a result:

(1) Since stiffness of a cylindrical sponge is small, the friction bearing with the ball embedded the cylindrical sponge, as a new bearing, is easy to control the damping ratio without change of the natural frequency;

(2) From the results of peak amplitude and RMS by experiments, the base isolation system using new friction bearings indicates better performance compared to this using previous friction bearings;

(3) The shape of waveforms except for the spike parts on numerical analysis is similar to that on excitation experiment;

(4) All waveforms on excitation experiments include nonlinier effects by friction force.

\section{References}

[1] Z. Ma, P. Cooper, D. Daly, L. Ledo, Existing building retrofits: Methodology and state-of-the-art, Energy and Buildings 55 (2012) 889-902.

[2] B. Myslimaj, S. Gamble, D. Chin-Quee, A. Davies, B. Breukelman, Base isolation technologies for seismic protection of museum artifacts, in: The 2003 IAMFA Annual Conference in San Francisco, International Association of Museum Facilities Administrators (IAMFA), California, Sep. 21-24, 2003.

[3] S. Ueda, M. Akimoto, T. Enomoto, T. Fujita, Study of roller type seismic isolation device for works of art, Trans. Jpn. Soc. Mech. Eng. Series C 71 (703) (2005) 807-812. (in Japanese )

[4] S. Fujita, Y. Morikawa, I. Shimoda, S. Nagata, H. Shimosaka, Isolation system for equipment using friction pendulum bearings (1st report, Shaking tests and response analysis on isolated equipment), Trans. Jpn. Soc. Mech. Eng. Series C 59 (557) (1993) 11-16. (in Japanese)

[5] S. Fujita, H. Yamamoto, N. Kitagawa, H. Kurabayashi, Research and development of the friction pendulum isolation device with poly-curvature (investigation of isolation performance on shake test and response analysis using vending machine model), Trans. Jpn. Soc. Mech. Eng., Series C 69 (2003) 50-56. (in Japanese)

[6] S. Aoki, T. Otaka, Y. Nakanishi, T. Nishimura, M. Inagaki, M. Kanazawa, Reduction method of seismic response with friction bearing, Proceedings of the Japan Society of Mechanical Engineers (Kanto), Fundamental Experiment Report No. 060-1, 2006, pp. 485-486. (in Japanese)

[7] K. Kurita, S. Aoki, Y. Nakanishi, K. Tominaga, M. Kanazawa, Fundamental characteristics of reduction system for seismic response using friction force, Journal of Civil Engineering and Architecture 5 (11) (2011) 1042-1047. 